\title{
The relationship between the National Senior Certificate and the National Benchmark Test for accounting students at a South African university
}

\author{
Riley Carpenter \\ Lily Roos \\ College of Accounting, University of Cape Town, South Africa
}

\begin{abstract}
Key Words
accounting students; determinants of success; higher education; National Benchmark Test (NBT); National Senior Certificate (NSC); South Africa
\end{abstract}

\begin{abstract}
The South African accounting profession needs racial transformation. Consequently, students pursuing the chartered accountant (South Africa) (CA(SA)) designation, especially at-risk Black students, require adequate support. To be successful, the support must be driven by factors influencing students' academic performance. As prior academic performance is one such factor, this study examines the relationship between the National Senior Certificate (NSC) exams and the National Benchmark Test (NBT) for students enrolled in an accounting degree at a South African university. Due to numerous moderate and strong correlations between NSC and NBT results, without multicollinearity, it was concluded that both sets of results should be considered as factors contributing to students' academic performance. The findings highlight the need for further empirical research on NSC and NBT results as determinants of success for accounting students.
\end{abstract}

\section{Introduction}

Racial transformation of the accounting profession has become a national priority in South Africa, particularly in the recent past. Consequently, promising students from various ethnic backgrounds have been assisted within their higher education studies. Promoting equality and redressing South Africa's past injustices is imperative for the country.

Significant progress has been made in South African tertiary education in recent years, and university access has improved for Black South Africans (South African Institute of Race Relations, 2019). However, greater access has not necessarily translated into equitable and timely graduation (Neethling, 2015). The Department of Higher Education and Training (2014) uses the composite term 'Black' to refer to the racial descriptors of African, Coloured and Indian/Asian people. Along with White, these racial descriptors are used for planning, monitoring and funding in South Africa.

Identifying the factors that influence students' academic success is vital in order to assess degree applications and the allocation of available capacity to at-risk students. Students who would otherwise be deprived of the opportunity to study accounting could also be supported through innovative programme structure and the provision of additional assistance (financial and other). It is hoped that such initiatives will result in more equitable educational outcomes in the country.

The single best predictor of academic performance at every level is academic performance in the immediately preceding year of study, as confirmed by numerous studies. In South Africa, for university entrants, this means performance in the National Senior Certificate (NSC) exams - the final secondary education assessments. However, higher education institutions also use access and placement tests as a diagnostic tool to enrol students in the most appropriate programmes. In South Africa, this is the National Benchmark Test (NBT), including proficiency scores for academic literacy (AL), quantitative literacy (QL) and mathematics (MAT). Due to the unclear interpretation of these two sets of results, it is uncertain which results are most informative in predicting academic success in accounting programs, and which results indicate who will need targeted support upon entry to university. Alternatively, these results could be a repetition of each other, with one being superfluous. 
This study focuses on the relationship between NSC and NBT results for students registered for an accounting degree at a South African university. The university is known for its large classes, and students who come to lectures with a diverse range of prior knowledge (Müller, Prinsloo, \& du Plessis, 2007; Scott, Yeld, \& Hendry, 2007). This study is motivated by three factors: (1) the dearth of research in accounting education on NSC and NBT results, (2) the contribution of the authors to the placement of university applicants in specified programmes, and (3), the desire to use both NSC and NBT results as part of the explanatory variables to consider determinants of students' academic success. Using a quantitative methodology within the framework of Biggs' 3P model, this study addressed the following two questions: (1) Is there a correlation between NSC and NBT results? (2) Is there multicollinearity between any of the NSC and NBT results?

This study commences by reviewing existing research on prior academic performance preceding entry to university. The research method is then discussed, followed by the results, conclusion and study limitations. The study concludes with recommendations for future research.

\section{Literature review \\ Biggs' 3P Model}

Numerous factors influence students' success in tertiary education. Biggs' 3P Model of student learning describes three sets of factors affecting student performance: (i) presage, (ii) process and (iii) product or performance (Biggs, 1985, 1987). This model has been often applied in accounting education (Davidson, 2002; Papageorgiou, 2017; Pullen, Toerien, \& Anthony, 2015). Presage factors are external to the learning environment. They include personal factors (e.g., intelligence, background or demographics) and situational factors (e.g., subject content or course structure). Process factors reflect the student's study approach (surface, achieving or deep approach). Performance or product factors can be cognitive (knowledge and intellect) or affective (how the student experiences learning) (Biggs, 1985).

Biggs (1987) places greatest emphasis on the learning approach of students, although he does acknowledge that presage factors can also strongly affect the development of learning approach. Therefore, factors such as age, language, race (Papageorgiou, 2017), locus of control (Carpenter \& Kunaka, 2018) and self-efficacy (Carpenter \& Shamsoodien, 2021; Shamsoodien \& Carpenter, 2020) determine the students' learning approach. This, in turn, influences their academic performance, both in public and private universities in South Africa (Carpenter \& Kraus, 2020).

\section{Academic performance}

Student endogenous factors and their effect on academic performance at an undergraduate level have been researched both in South Africa and internationally. Factors identified include age, gender, race, home language, whether accounting was selected as a Grade 12 subject, performance in Grade 12 Accounting, performance in Grade 12 Mathematics and overall Grade 12 performance. Grade 12 results are the NSC results.

Numerous studies have reported that students who took Accounting prior to university outperformed those who studied it for the first time at university (Bokana \& Tewari, 2014; Papageorgiou, 2017; Papageorgiou \& Carpenter, 2019; Yanbarisova, 2014). Some international studies support this finding (Byrne \& Flood, 2008), while others contradict it (Douglas, 2017; Koh \& Koh, 1999). This advantage, however, dissipates after the first year of undergraduate study, both in South Africa (Jansen \& de Villiers, 2016; Papageorgiou \& Halabi, 2014) and internationally (Doran, Bouillon, \& Smith, 1991). This could be due to the more advanced nature of second- and third-year accounting courses.

NSC mathematics performance has also been positively correlated with South African university accounting course performance (Bokana \& Tewari, 2014; Papageorgiou \& Halabi, 2014; Swart \& Becker, 2014; Tewari, 2015). This is supported by international studies in the UK (Guney, 2009), Singapore (Koh \& Koh, 1999) and Malaysia (Ismail et al., 2017). Like with accounting, the relationship wanes the further the student progresses in their studies-both in the final undergraduate year and at postgraduate level (Jansen \& de Villiers, 2016; Pullen et al., 2015).

Overall performance in Grade 12 (often measured by grade point average (GPA)) is strongly correlated with academic success at all levels of tertiary education (Bokana \& Tewari, 2014; Jansen \& De Villiers, 2016; Pullen et al., 2015). van Rooy and Coetzee-van Rooy (2015) clarify that these NSC results are 
a strong predictor of success at university only for strong students (those who achieved an average of at least $65 \%$ ). The prediction value is much weaker for students who achieve an average of less than $65 \%$; some of these students go on to perform well at university while others fail. This may be due to more qualitative factors-such as grit, motivation and maturity-playing a larger role in these students' success.

A large body of research has affirmed that the single best predictor of academic performance at every level is academic performance in the preceding year of study. Studies have confirmed this in South African undergraduate courses (Jansen \& de Villiers, 2016; Papageorgiou \& Halabi, 2014; Swart \& Becker, 2014), postgraduate courses (Pullen et al., 2015; Steenkamp, 2014; Swart \& Becker, 2014) and professional exams (Dehrmann, 2013; van Wyk, 2011). The strong link between prior performance and academic success may be due to the hierarchical knowledge structure applicable in accounting (Myers, 2017), as confirmed by international research at the university level (Archambault \& Archambault, 2016; Byrne \& Flood, 2008; Doran et al., 1991; Koh \& Koh, 1999; Maksy \& Wagaman, 2016) and professional exam level (Douglas, 2017; Rodrigues, Pinho, Bugarim, Craig, \& Machado, 2018).

\section{National Benchmark Test}

Assessing students' academic preparedness before admission to university ensures appropriate placement and a definite chance for academic success (Ndebele et al., 2013). South African higher education institutions use the NBT as a diagnostic tool to enrol students in the most appropriate qualification and to determine whether additional support is required to aid academic success (Centre for Educational Testing for Access and Placement, 2018). The NBT represents the point at which students are most likely to be prepared for university. The test classifies the results into three categories-basic, intermediate or proficient.

The NBT evaluates students' proficiency in AL, QL and MAT. AL is the students' capacity to engage successfully with the demands of academic study, and includes learning, comprehension, application and synthesis of new knowledge. QL is the students' ability to identify and solve problems in quantitative situations relevant to higher education study. MAT assesses students' competence in more complex mathematical topics (Ndebele et al., 2013; Ogbonnaya \& Awuah, 2019).

The body of research on NSC and NBT results in South Africa can be split into two groups: (1) studies that look at the contribution of NBT and NSC to students' academic performance and (2) studies that look at how the former is affected by a support or intervention module, introduced due to poor NBT results.

There is contrasting evidence on NBT results as a factor influencing tertiary education performance across a broad spectrum of disciplines. In first-year economics, it was asserted that for students who achieved NSC mathematics scores close to the minimum university entrance requirement, the NBT scores should carry more weight to gauge the student's true potential (Rankin, Schoer, Sebastiao, \& Van Walbeek, 2012). However, in a first-year mathematics course, neither the NBT MAT nor the NSC results were informative independent variables of success (Mahlobo, 2015).

Looking further afield, in physiology it was found that excellent performance in NSC English, life sciences and the NBT QL were significant indicators of academic achievement, whereas mathematics and physical sciences were not (Allers, Hay, \& Janse van Rensburg, 2016). A more recent study on first-year medical students' academic success found that even though the NBT MAT was not a significant predictor, the combination of NSC and NBT results had higher explanatory power (Mabizela \& George, 2020).

Most studies on support or intervention modules, coupled with NSC and/or NBT results, conclude favourably on the effect of such interventions. A study at one South African university found that attending university academic literacy support modules was the most substantial independent variable in academic success in the first and second year, while the NBT AL results were positively correlated with other placement test results, signifying that only one of these tests should be used (van Rooy \& Coetzeevan Rooy, 2015).

There are sometimes differing results between the NSC English results and students' NBT AL performance, indicating that students may not be able to cope with the tertiary-level language of instruction (Cliff, 2014). Students who were classified as 'basic' and 'intermediate' in the NBT tests struggled with their studies in the absence of explicit AL interventions. This is because they found it 
difficult to understand the contextualised AL demands of reading and reasoning in higher education (Cliff, 2015).

In a psychology course, there was a definite improvement in performance for students on a QL intervention course whose NBT QL performance scores were in the lower proficiency bands (Mutakwa \& Mhakure, 2019).

\section{Concluding remarks on literature}

Academic performance in prior years of study, including the NSC results, is a good predictor of academic performance at university. Admissions that rely on NSC results alone may, on the one hand, exclude students with academic potential, while on the other hand, they may enrol students who are not sufficiently prepared. Including NBT results may help to identify students who are adequately prepared for university. Support and intervention modules clearly assist students. However, a drawback of both the NSC and NBT results is that they focus on current competencies, rather than future potential. The vast majority of studies in this area focus on first-year performance or progression, and no studies look at the impact further down the line, for example, time to graduation (Carpenter \& Roos, 2020).

What is clearly lacking in the research is a focus on accounting students. Before considering whether NSC and NBT results are good predictors of academic success for this sample of students, it is helpful to first consider the relationship between the different results. Therefore, the correlation of NSC and NBT results for accounting students must be tested, as well as any potential multicollinearity, before further testing in the form of a regression can be conducted.

\section{Methodology}

This quantitative study analysed data for 1120 students enrolled for the three-year BCom (Chartered Accountant) and four-year BCom (Chartered Accountant-extended) programmes at the University of Cape Town (UCT), South Africa for 2013 to 2016. The data was obtained from the UCT Institutional Planning Department after ethical clearance was provided. The data was analysed using Stata v16.

A Pearson's correlation test was run to assess the relationship between the three NSC results (Accounting, Mathematics and English) that are either significant from the literature or are part of the degree's entrance requirements, and the three NBT results (AL, QL and MAT). NSC GPA was not used as the data was unavailable. The NBT results were reported on a continuous scale rather than proficiency level. Before interpreting the results, the data was examined for the assumptions of Pearson's correlation (continuous variables, linear relationship, no significant outliers, and approximately normally distributed), which were all met.

The sample comprised 730 of the 1120 students. Of the 390 students who were removed, 1 was an erroneous record, 19 did not have NBT results, 256 were not South African, and 114 did not take Accounting as a school subject.

\section{Results and discussion}

In the discussion, only statistically significant correlations are mentioned. It should be noted that weak, moderate and strong correlation equates to small, medium and large effect sizes. In Table 1 it can be seen that there was a moderative positive correlation between all NSC results; NSC Mathematics and NSC Accounting, $r(728)=.439, p<0.0001$, NSC Mathematics and NSC English, $r(728)=.2087, p<0.0001$, and NSC Accounting and NSC English, $r(728)=.2344, p<0.0001$. This is in line with expectations, as students who perform well in one subject, and who gain entry to university normally perform well in the other subjects too. 
Table 1: Pearson's correlation matrix of the variables in the sample

\begin{tabular}{lllllll}
\hline & $\begin{array}{l}\text { NSC Acc } \\
(\mathrm{n}=730)\end{array}$ & $\begin{array}{l}\text { NSC Maths } \\
(\mathrm{n}=730)\end{array}$ & $\begin{array}{l}\text { NCS English } \\
(\mathrm{n}=730)\end{array}$ & $\begin{array}{l}\text { NBT AL } \\
(\mathrm{n}=730)\end{array}$ & $\begin{array}{l}\text { NBT QL } \\
(\mathrm{n}=730)\end{array}$ & $\begin{array}{l}\text { NBT MAT } \\
(\mathrm{n}=730)\end{array}$ \\
\hline NSC Acc & 1.0000 & & & & \\
\hline NSC Maths & $\begin{array}{l}0.4390 \\
\text { N }\end{array}$ & 1.0000 & & & \\
\hline NCS English & 0.2344 & 0.2087 & 1.0000 & & \\
& $0.0000^{*}$ & $0.0000^{*}$ & & & \\
\hline NBT AL & -0.0005 & 0.0652 & 0.3567 & 1.0000 & \\
& 0.9896 & 0.0785 & $0.0000^{*}$ & & \\
\hline NBT QL & 0.0584 & 0.3419 & 0.1883 & 0.4832 & 1.0000 & \\
& 0.1147 & $0.0000^{*}$ & $0.0000^{*}$ & $0.0000^{*}$ & & \\
\hline NBT MAT & 0.1721 & 0.6772 & 0.1989 & 0.2505 & 0.5389 \\
& $0.0000^{*}$ & $0.0000^{*}$ & $0.0000^{*}$ & $0.0000^{*}$ & $0.0000^{*}$ & \\
\hline
\end{tabular}

* $\mathrm{p}<0.0001$

Similarly, as per the data in Table 1, there was a moderative positive correlation between the NBT results, with the exception of NBT MAT and NBT QL, $r(728)=.5389, p<0.0001$, where the correlation was strong. As both the MAT and QL NBT test numeracy, this result was also not unexpected. What is interesting is that there was only a moderative positive correlation between NBT AL and NCS English, $r(728)=.3567, p<0.0001$, but limited correlation with the other NSC results. As the NBT AL tests academic reading and reasoning abilities, assessing students' capabilities of engaging successfully with higher education language demands (Cliff, 2015), the association with NSC English is encouraging.

There was a moderate positive correlation between both NBT QL and NCS Mathematics $(\mathrm{r}(728)=.3419, \mathrm{p}<0.0001)$ and surprisingly, NCS English $(\mathrm{r}(728)=.1883, \mathrm{p}<0.0001)$. It may be that the problem-solving nature of the NBT QL is similar to the skills required in NSC English. The lack of significant correlation between both NBT AL and QL and NSC Accounting stands out, as NSC Accounting is a strong predictor of academic performance for accounting students at university and the NBTs are supposed to test students' ability to cope with tertiary education. This could be explained by the NSC being norm-referenced while the NBT is criterion-referenced (Prince, 2017). Thus, the interpretation of the results varies. This is because norm-referenced tests differ from criterion-referenced tests in terms of purpose, content selection, and nature of scoring (Bond, 1996). The purpose of the NSC is to sort and rank students. In contrast, the NBT aims to demonstrate students' performance in clearly defined domains that require mastery (Bond, 1996; Foxcroft \& Roodt, 2013).

The positive correlation between NBT MAT and the NSC results was moderate for NSC Accounting $(\mathrm{r}(728)=.1721, \mathrm{p}<0.0001)$ and English $(\mathrm{r}(728)=.1989, \mathrm{p}<0.0001)$, but strong for Mathematics $(\mathrm{r}(728)=.6772$, $\mathrm{p}<0.0001)$. Once again, the lack of a strong correlation with accounting needs further investigation.

Therefore, the numerous correlations indicate that all NSC and NBT results should be considered as presage factors contributing to students' learning approaches. Consequently, they may impact academic performance.

While assessing multicollinearity is usually performed as part of a regression model, the motivation of this study to use both NSC and NBT results as part of explanatory variables of students' academic success warrants further investigation to ascertain whether two or more of these variables are highly linearly related. The strong correlation between NSC Mathematics and NBT MAT, and between NBT MAT and NBT QL may affect the reliability of a regression model in future research. Table 2 provides the multicollinearity assessment. All variance inflation factors (VIF) are below 5, indicating that the different results are measuring different aspects of students' ability and potential, and all variables can be used for a regression model. 
Table 2: Collinearity diagnostics

\begin{tabular}{lllll}
\hline Variable & VIF & SQRT VIF & Tolerance & $\mathrm{R}^{2}$ \\
\hline NSC Acc & 1.33 & 1.15 & 0.7505 & 0.2495 \\
NSC Maths & 2.36 & 1.54 & 0.4230 & 0.5770 \\
NCS English & 1.24 & 1.11 & 0.8075 & 0.1925 \\
NBT AL & 1.50 & 1.23 & 0.6664 & 0.3336 \\
NBT QL & 1.73 & 1.32 & 0.5776 & 0.4224 \\
NBT MAT & 2.38 & 1.54 & 0.4201 & 0.5799 \\
Mean VIF & 1.76 & & & \\
\hline
\end{tabular}

\section{Conclusion}

This study highlighted the importance of understanding factors affecting accounting students' academic success. To develop targeted interventions to assist students, it is paramount to first identify the factors of academic success. Biggs' $3 \mathrm{P}$ model demonstrates that many presage factors affect academic performance, including age, gender, race, language and prior academic results.

In South Africa, prior academic results for university constitute both secondary school-leaving results, the NSC results, and the placement test-the NBT. The NSC results relevant to accounting students include English, Mathematics and Accounting, while the three NBT domains are AL, QL and MAT.

This study investigated the relationship between NSC and NBT results. The two research questions of whether correlation and multicollinearity exist between the results were answered. The findings indicated numerous moderate and strong correlations between the many NSC and NBT pairings. Therefore, these could be presage factors that contribute to our understanding of students' academic success. While the two strong correlations may indicate redundancy, that is, the results are measuring the same thing, multicollinearity was not found.

The results of this study may guide lecturers when considering admission requirements for university. Even though there are many other researched factors that affect students' academic performance, such factors are difficult to measure, notably students' attitudes, strategies, skills and behaviours, which cannot be ascertained through grading, scores or standardised testing (Fook \& Sidhu, 2015; York, Gibson, \& Rankin, 2015). Unfortunately, there are no assurances of academic success because each student is different, and brings with them, and is exposed to, their own unique experiences.

\section{Limitations and areas for future research}

The scope of this study is limited to a correlation test. The next clear step is to test the impact of the NSC and NBT results on students' academic performance. Thereafter, the significant NSC and NBT results should be included in a regression with the other researched significant factors contributing to academic success, and their impact should then be investigated.

Other limitations include the study's focus on one university in South Africa. Consequently, the results considered are only a part of other factors affecting students' academic performance.

\section{References}

Allers, N. J., Hay, L., \& Janse van Rensburg, R. C. (2016). Preliminary study: Predictors for success in an important premedical subject at a South African medical school. African Journal of Health Professions Education, 8(1), 81. https://doi.org/10.7196/ajhpe.2016.v8i1.647

Archambault, M., \& Archambault, J. (2016). Senior Level Accounting Course Performance and the Timing of Completing Intermediate Accounting II. International Journal of Accounting and Taxation, 4(2), 12-24. https://doi.org/10.15640/ijat.v4n2a2

Biggs, J. B. (1985). The role of metalearning in the study processes. British Journal of Educational Psychology, 55(2), 185212.

Biggs, J. B. (1987). Student approaches to learning and studying. Research Monograph. Australian Council for Educational Research. Retrieved from https://eric.ed.gov/?id=ED308201 
Bokana, K. G., \& Tewari, D. D. (2014). Determinants of Student Success at a South African University: An Econometric Analysis. Anthropologist, 17(1), 259-277.

Bond, L. (1996). Norm- and Criterion-Referenced Testing. Practical Assessment, Research, and Evaluation, 5(2). https:/ / doi.org/https:/ / doi.org/10.7275/dy7r-2x18

Byrne, M., \& Flood, B. (2008). Examining the relationships among background variables and academic performance of first year accounting students at an Irish University. Journal of Accounting Education, 26(4), $202-212$. https://doi.org/10.1016/j.jaccedu.2009.02.001

Carpenter, R., \& Kraus, T. (2020). Potential determinants of students' academic success in private tertiary education in South Africa. In 5th International Conference on Globalization, Entrepreneurship and Emerging Economies (ICGEEE) (pp. 69-78). Online. https://doi.org/10.24052/BMR/V11NU02/ART-09

Carpenter, R., \& Kunaka, S. (2018). Gender-differentiated locus of control in a racially diverse accounting student body at a South African university. In 30th Annual Conference of the Southern African Institute of Management Scientists (SAIMS) (pp. 16-29). Stellenbosch. https://doi.org/ISBN: 978-0-7972-1729-4

Carpenter, R., \& Roos, L. (2020). Can We Afford It? The association between financial aid and time to completion in Accounting Higher Education in South Africa: A literature review. In 9th International Conference on Business and Economic Development (ICBED) (pp. 222-232). New York. https://doi.org/10.24052/BMR/V11NU01/ART-24

Carpenter, R., \& Shamsoodien, S. (2021). The relationship between self-efficacy and accounting students' academic performance at a South African university. In 7th International Conference on Higher Education Advances (HEAd'21) (pp. 67-74). València. https://doi.org/10.4995/HEAd21.2021.12922

Centre for Educational Testing for Access and Placement (CETAP). (2018). The National Benchmark Tests National Report: 2018 Intake Cycle. Cape Town. Retrieved from

https://nbt.ac.za/sites/default/files/NBTPReport_2018.pdf

Cliff, A. (2014). Entry-level students reading abilities and what these abilities might mean for academic readiness. Language Matters, 45(3), 313-324. https:/ / doi.org/10.1080/10228195.2014.958519

Cliff, A. (2015). The national benchmark test in academic literacy: How might it be used to support teaching in higher education? Language Matters, 46(1), 3-21. https:/ / doi.org/10.1080/10228195.2015.1027505

Davidson, R. A. (2002). Relationship of study approach and exam performance. Journal of Accounting Education, 20(1), 29-44. https://doi.org/10.1016/S0748-5751(01)00025-2

Dehrmann, L. (2013). Predictors of examination success in the SAICA qualifying examinations. Stellenbosch University. Retrieved from http://scholar.sun.ac.za/handle/10019.1/80094?show=full

Department of Higher Education and Training. (2014). Report of the Ministerial Committee for the Review of the Funding of Universities. Pretoria.

Doran, B. M., Bouillon, M. L., \& Smith, C. G. (1991). Determinants of student performance in accounting principles I and II. Issues in Accounting Education, 6(1), 74-84.

Douglas, S. (2017). Does an accounting degree add up? An investigation into the professional exam performance and nontechnican skill development of accounting degree graduates. Robert Gordon University.

Fook, C. Y., \& Sidhu, G. K. (2015). Investigating Learning Challenges Faced by Students in Higher Education. In Procedia - Social and Behavioral Sciences (Vol. 186, pp. 604-612). Elsevier B.V.

Foxcroft, C., \& Roodt, G. (2013). Introduction to Psychological Assessment in the South African Context 4e (4th ed.). Cape Town: Oxford University Press.

Guney, Y. (2009). Exogenous and Endogenous Factors Influencing Students' Performance in Undergraduate Accounting Modules. Accounting Education, 18(1), 51-73. https://doi.org/10.1080/09639280701740142

Ismail, P. M., Mohammed, N. F., Ahmad, M., \& Yatim, N. (2017). Prior Academic Performance and Passing Professional Accounting Examinations : Empirical Evidence from Malaysia. Accounting and Finance Review, 2(2), 1-8.

Jansen, J., \& De Villiers, C. (2016). Determinants of student performance in an accounting degree programme. South African Journal of Accounting Research, 30(1), 1-28. https://doi.org/10.1080/10291954.2015.1019223

Koh, M. Y., \& Koh, H. C. (1999). The determinants of performance in an accountancy degree programme. Accounting Education, 8(1), 13-29.

Mabizela, S. E., \& George, A. Z. (2020). Predictive validity of the National Benchmark Test and National Senior Certificate for the academic success of first-year medical students at one South African university. BMC Medical Education, 20(1), 1-10. https:/ / doi.org/10.1186/s12909-020-02059-8

Mahlobo, R. (2015). National benchmark test as a benchmark tool. In 2015 ISTE International Conference on Mathematics Science and Technology (pp. 261-273).

Maksy, M. M., \& Wagaman, D. D. (2016). Factors Associated with Student Performance in Upper Level Undergraduate Accounting Courses: An Empirical Comparative Study at Commuter and Residential Schools. Journal of Applied Business and Economics, 18(5), 57-79. https:/ / doi.org/10.1108/10309610810891328 
Müller, H., Prinsloo, P., \& du Plessis, A. (2007). Validating the profile of a successful first year accounting student. Meditari Accountancy Research, 15(1), 19-33. https:/ / doi.org/10.1108/10222529200700002

Mutakwa, D. T., \& Mhakure, D. (2019). Tracking students' performance in higher education: The transition from national benchmark tests to quantitative literacy intervention course. South African Journal of Higher Education, 33(4), 203-218. https://doi.org/10.20853/33-4-2892

Ndebele, N., Badsha, N., Figaji, B., Gevers, W., Pityana, B., \& Scott, I. (2013). A proposal for undergraduate curriculum reform in South Africa: The case for a flexible curriculum structure. Pretoria.

Neethling, L. (2015). The determinants of academic outcomes: A competing risks approach. In Proceedings of the 2015 Conference of the Economic Society of South Africa (pp. 1-17). Cape Town.

Ogbonnaya, U. I., \& Awuah, F. K. (2019). Quintile ranking of schools in South Africa and learners' achievement in probability. Statistics Education Research Journal, 18(1), 106-119.

Papageorgiou, E. (2017). Accounting students' profile versus academic performance: A five-year analysis. South African Journal of Higher Education, 31(3), 31-33. https:/ / doi.org/10.20853/31-3-1064

Papageorgiou, E., \& Carpenter, R. (2019). Prior accounting knowledge of first-year students at two South African universities: Contributing factor to academic performance or not? South African Journal of Higher Education, 33(6), 249-264. https://doi.org/10.20853/33-6-3032

Papageorgiou, K., \& Halabi, A. (2014). Factors contributing toward student performance in a distance education accounting degree. Meditari Accountancy Research, 22(2), 211-223. https:/ / doi.org/10.1108/MEDAR-08-2013-0032

Prince, R. (2017). The relationship between school-leaving examinations and university entrance assessments: The case of the South African system. Journal of Education, 70, 133-160.

Pullen, E., Toerien, F., \& Anthony, J. (2015). Student Endogenous Factors that Impact on Performance in Advanced Management Accounting: An Exploratory Study. In 2015 SAAA/IAAER Biennial Conference (pp. 604-621). Retrieved from http:/ / www.saaa.org.za/ConferencePublications?Confid=7

Rankin, N., Schoer, V., Sebastiao, C., \& Van Walbeek, C. (2012). Predictors of academic performance : National Senior Certificate versus National Benchmark Test. South African Journal of Higher Education, 26(3), 564-585.

Rodrigues, L. L., Pinho, C., Bugarim, M. C., Craig, R., \& Machado, D. (2018). Factors affecting success in the professional entry exam for accountants in Brazil. Accounting Education, 27(1), 48-71. https://doi.org/10.1080/09639284.2017.1361851

Scott, I., Yeld, N., \& Hendry, J. (2007). A case for improving teaching and learning in South African higher education. Pretoria.

Shamsoodien, S., \& Carpenter, R. (2020). Do Beliefs Matter in Accounting? Self-efficacy and Student Academic Performance in Accounting Higher Education in South Africa: A Literature Review. In 2020 Southern African Accounting Association National Teaching and Learning and Regional Conference Proceedings in association with the Meditari Accountancy Research Conference (pp. 479-495). Online. ISBN: 978-0-620-90856-6

Steenkamp, G. (2014). How pre-admission characteristics affect the performance of CTA students at a South African university. Journal of Economic and Financial Sciences, 7(2), 283-298.

Swart, O., \& Becker, A. I. (2014). Matric results in mathematics and languages: A predictor of undergraduate and postgraduate success. Progressio, 36(1), 157-181.

Tewari, A. R. (2015). African female students' experiences of introductory accounting modules at UniZulu. Univerisity of Zululand.

The South African Institute of Race Relations. (2019). Free Facts: South Africa - a qualified success (The South African Institute of Race Relations Free Facts report No 3/2019 Issue 11).

van Rooy, B., \& Coetzee-van Rooy, S. (2015). The language issue and academic performance at a South African University. Southern African Linguistics and Applied Language Studies, 33(1), 31-46.

van Wyk, E. (2011). A Note: The SAICA Part I Qualifying Examinations: Factors that may influence candidates' success. South African Journal of Accounting Research, 25(1), 145-174.

https:/ / doi.org/10.1080/10291954.2011.11435157

Yanbarisova, D. M. (2014). Combining University Studies With Work: Influence on Academic Achievement (BPRR 21 EDU/2014). https://doi.org/http://dx.doi.org/10.2139/ssrn.2535776

York, T. T., Gibson, C., \& Rankin, S. (2015). Defining and Measuring Academic Success. Practical Assessment, Research $\mathcal{E}$ Evaluation, 20(5), 1-20. 